\title{
LŪPŲ BALZAMŲ SU MARGALAPĖS AKTINIDIJOS IR PAPRASTOSIOS AVIETĖS LIOFILIZUOTOMIS UOGOMIS MODELIAVIMAS IR KOKYBE்S VERTINIMAS
}

\author{
Birutė Pockevičiūtė, Rugilė Leonavičiūtė \\ Kauno kolegijos Medicinos fakulteto Farmakotechnikos katedra
}

Raktažodžiai: lūpų balzamas, margalapė aktinidija, paprastoji avietè.

\section{Santrauka}

Natūralios kilmès preparatai sukelia mažiau alerginių susirgimų, apsaugo nuo mikroorganizmų patekimo ị organizmą. Lūpų oda labai plona, todèl labiau veikiama daugybès išorinių veiksnių, dèl kurių dažnai gali atsirasti pigmentinių dėmių, îtrūkimų ar netgi pūslių. Remiantis novatoriška bei natūralios kilmès koncepcija, sumodeliuotos lūpų odos priežiūrai tinkamos pusiau kietos vaisto formos - lūpų balzamai. Tyrimo objektas - du skirtingos sudèties laboratorijoje pagaminti suspensiniai lūpų balzamai. Tyrimo tikslas - sukurti pusiau kietas vaisto formas su margalapès aktinidijos, paprastosios avietès liofilizuotų uogų milteliais, ịvertinti jų pH reikšmes ir stabilumą, laikant skirtingoje temperatūroje pagaminus, po 45 ir 90 dienų. Lūpų balzamų gamybai pasirinktos natūralios kilmès medžiagos: bičių vaškas, taukmedžio sviestas, kakavos sviestas, saldžiujjų migdolų aliejus, natūralus bičių medus, tokoferolio acetatas ir liofilizuotų paprastųų aviečių bei margalapių aktinidijų uogų milteliai, kurie balzamams suteikè spalvą ir kvapą. Lūpų balzamai pagaminti lydymo būdu, komponentus lydant virš vandens vonelès lydymosi temperatūros mažèjimo tvarka, pabaigoje įdedant bičių medaus, tokoferolio acetato ir liofilizuotų uogų miltelių. Atlikus juslinių savybių tyrimą atskleista, kad lūpų balzamas, kuriame yra paprastưjų aviečių liofilizuotų uogų miltelių, respondentams labiau patiko dèl konsistencijos, kvapo ir spalvos, nei lūpų balzamas, ị kurio pagrindą įdèta margalapès aktinidijos liofilizuotų miltelių. Atlikus pH reikšmių tyrimą nustatyta, kad lūpų balzamai pasižymi silpnai rūgštinèmis savybèmis. Galima daryti išvadą, kad pagamintus preparatus tikslinga vartoti mikroorganizmų sukeltiems pažeidimams gydyti ir apsaugoti nuo išorinių veiksnių. Atliktas stabilumo tyrimas atskleidè, kad pagaminti preparatai tinkami vartoti iki 45 dienų.

\section{İvadas}

Lūpų odos struktūra skiriasi nuo kitose žmogaus kūno vietose esančios odos struktūros. Ji labai plona, turi mažiau melanocitų ir veikiama daugybės išorinių veiksnių, dẻl kurių dažnai sutrinka apsauginè lūpų odos funkcija. Sutrikus šiai funkcijai, oda tampa sausa, šerpetojanti, joje atsiranda pigmentinių dẻmių, ịtrūkimų [4]. Lūpų odą stipriai veikia ultravioletiniai saulès spinduliai, temperatūros svyravimai, cheminiai junginiai, kurie gali sukelti alergines reakcijas. Ivairaus amžiaus žmonèms aktualu naudoti lūpų odą saugančius preparatus, kuriuose būtų veikliujų medžiagų, pasižyminčių antioksidaciniu, antiuždegiminiu, antivirusiniu, antibakteriniu bei drèkinamuoju ir maitinamuoju poveikiu [6-8].

Remiantis moksliniais šaltiniais, lūpų balzamų gamybai reikalingi antioksidantai, konservantai, kvapų reguliavimo medžiagos, dažikliai, pigmentai. I̦ kai kuriuos preparatus dedama nuo ultravioletinių saulès spindulių apsaugančių medžiagų ir kt. Be to, lūpų balzamų gamyboje pasitaiko ir sintetinių junginių, tokių kaip skystasis parafinas, sintetinis aliejus, tačiau jie naudojami vis rečiau, kadangi gali sukelti nepageidaujamus simptomus, pavyzdžiui, paraudimą, patinimą, niežulị [3].

Augalinès kilmès preparatų vertę lemia ne tik jų gebėjimas gydyti nepageidaujamus lūpų odos simptomus, bet ir jusline patirtis, labiausiai priklausoma nuo lūpų balzamų sudèties, komponentų kiekio bei kokybès. Lūpų balzamų esminiai veiksniai, lemiantys jų pasirinkimą, yra malonus kvapas, spalva, konsistencija, atsparumas slydimui, stabilumas, vientisumas, natūralios prigimties komponentai bei jų farmakologinis poveikis [5].

Lūpų balzamai turi atitikti juslinius ir stabilumo reikalavimus, tokius kaip atsparumas temperatūros pokyčiams, ma- 
lonus skonis, kvapas, glotnumas tepimo metu, lipnumas. Jie turi būti lengvai pašalinami nuo plonos lūpų odos. Funkciniai sudèties komponentai dažniausiai lemia preparatų tekstūrą ir išvaizdą. Pavyzdžiui, įdejjus skirtingą vaško kiekị, lūpų balzamo pagrindas gali pakeisti tekstūrą ir išvaizdą, todèl galima gauti skirtingos paskirties dermatologinius produktus [4].

Lūpų balzamų gamybai svarbu pasirinkti tarpusavyje derančias medžiagas. Natūralios kilmès bičių vaškas dažniausiai naudojamas kaip pagalbinis dermatologinių preparatų komponentas, atliekantis emulgavimo funkciją. Remiantis moksline literatūra, lūpų balzamų pagrindo gamyboje dažnai naudojamas kietos konsistencijos taukmedžio sviestas ir kakavos sviestas [2]. Bičiu medus sudarytas iš 19 proc. vandens ir 81 proc. sausųjų medžiagų. Medaus sudètyje gausu mineralinių medžiagų, tokių kaip kalis, kalcis, geležis, natris, magnis, bei vitaminų PP, C, B1, B2, B6. Be to, meduje nustatyti nedideli aminorūgščiu (fenilalanino, prolino), aromatinių ir baktericidinių medžiagų kiekiai [9].

Pagrindinès lūpų balzamų sudedamosios dalys yra riebalų rūgštys, pavyzdžiui, vaškas, aliejus ir sviestas, kurie preparatui suteikia konsistenciją [2].

Tyrimo tikslas - sukurti pusiau kietas vaisto formas su margalapès aktinidijos, paprastosios avietès liofilizuotų uogų milteliais, įvertinti jų $\mathrm{pH}$ reikšmes ir stabilumą pagaminus, po 45 ir 90 dienų.

\section{Tyrimo objektas ir metodai}

Tyrimo objektas - du skirtingos sudèties laboratorijoje pagaminti suspensiniai lūpų balzamai.

Lūpų balzamų pagrindas gaminamas lydymo būdu. Jų sudèties komponentai lydomi ir maišomi lydymosi temperatūros mažejimo tvarka. Pirmiausia ištirpinamas bičių vaškas, po to taukmedžio sviestas ir kakavos sviestas. I ištirpusius ir atvėsintus komponentus įmaišoma saldžiųjų migdolų aliejaus. Kad temperatūra nepaveiktų medaus struktūros, šis komponentas įmaišomas vienas iš paskutiniujų. I pagamintą preparatų pagrindą ịpilama tokoferolio acetato ir liofilizuotų uogų miltelių (lūpų balzamui „A“ įmaišomi paprastosios avietès liofilizuoti uogų milteliai, o lūpų balzamui „B“ - margalapès aktinidijos liofilizuoti uogų milteliai). Šie komponentai dedami technologinio proceso pabaigoje. Milteliai įmaišomi ị išlydytus, nuimtus nuo vandens vonelès ir atvėsusius komponentus, tokiu būdu apsaugant veikliuosius junginius nuo aukštos temperatūros poveikio.

Atliekant lūpų balzamų juslinių savybių tyrimą, taikytas anoniminès anketinès apklausos metodas. Tyrimo metu apklausti Kauno miesto gyventojai, kurie analizavo laboratorijoje pagamintų lūpų balzamų juslines savybes: kvapą, spalvą bei konsistenciją. Juslinių savybių tyrime dalyvavo 120 respondentų, analizavusių laboratorijoje pagamintų lūpų balzamų kvapą, spalvą, konsistenciją. Tyrime dalyvavo 89 moterys ir 31 vyras. Pagal amžiaus grupes, daugiausia respondentų (47,50 proc.) buvo 18-25 metų.

Lūpų balzamai turi išlaikyti savo tekstūrą ir nesilydyti iprastineje kambario temperatūroje. Remiantis Europos farmakopejja, lūpų balzamų lydymosi temperatūra turi būti panaši arba didesnè nei lūpų paviršiaus temperatūra, kuri yra $32 \pm 1^{\circ} \mathrm{C}$. Lūpų balzamų lydymosi temperatūrai nustatyti naudojama vandens vonelè, porceliano lëkšstelè ir termometras. Mèginys dedamas ị porceliano lèkštelę virš vandens vonelès. Europos farmakopejoje nurodoma, kad momentas, kai iš lūpų balzamo susiformuoja lašas, laikomas jo lydymosi temperatūra. Matavimai atlikti 3 kartus, apskaičiuotas aritmetinis vidurkis bei standartinè paklaida [1].

Lūpų balzamų $\mathrm{pH}$ reikšmès matuotos naudojant $\mathrm{pH}$-metrą. 4 gramus lūpų balzamo mėginio šildant vandens vonelèje, ištirpinta $40 \mathrm{ml}$ išgryninto vandens. Gautas tirpalas filtruotas, o filtratui atvėsus, pamatuota $\mathrm{pH}$ reikšmé. Atliekant $\mathrm{pH}$ tyrimą, ị stiklinę su mėginiu įmerkiamas elektrodas ir fiksuojama pH reikšmè. Po kiekvieno matavimo elektrodas nuplaunamas išgrynintu vandeniu. Kiekvienam mėginiui atlikti 3 matavimai ir išvesti aritmetiniai vidurkiai, nustatyta standartinè paklaida.

Stabilumo tyrimais siekiama įvertinti, ar pagamintas preparatas laikymo metu yra stabilus. Pagaminti lūpų balzamai

1 lentelè. Lūpų balzamų pH reikšmių rezultatai.

\begin{tabular}{|l|c|c|}
\hline \multirow{2}{*}{$\begin{array}{l}\text { pH matavimo } \\
\text { laikas ir } \\
\text { vidurkis }\end{array}$} & \multicolumn{2}{|c|}{$\begin{array}{r}\text { Lüpų balzamo su liofilizuotų uogụ } \\
\text { milteliais pH pokyčiai }\end{array}$} \\
\cline { 2 - 3 } & paprastosios avietės & margalapės aktinidijos \\
\hline Pagaminus & $6,66 \pm 0,02$ & $6,65 \pm 0,03$ \\
\hline Po 45 dienų & $6,71 \pm 0,04$ & $6,67 \pm 0,02$ \\
\hline Po 90 dienų & $6,74 \pm 0,03$ & $6,84 \pm 0,04$ \\
\hline Vidurkis & $6,70 \pm 0,03$ & $6,73 \pm 0,03$ \\
\hline
\end{tabular}

2 lentelè. Lūpų balzamų stabilumo tyrimo rezultatai.

\begin{tabular}{|c|c|c|c|c|}
\hline $\begin{array}{l}\text { Veiksniai ir } \\
\text { savybės }\end{array}$ & \multicolumn{4}{|c|}{$\begin{array}{c}\text { Lūpụ balzamas su paprastosios avietės } \\
\text { liofilizuotomis uogomis }\end{array}$} \\
\hline Temperatūra & \multicolumn{2}{|c|}{$5 \pm 1^{0} \mathrm{C}$} & \multicolumn{2}{|c|}{$18-25^{\circ} \mathrm{C}$} \\
\hline Laikymo laikas & 45 dienos & 90 dienų & 45 dienos & 90 dienų \\
\hline Kvapas & Nepakito & Nepakito & Nepakito & Pakito \\
\hline Spalva & Nepakito & Nepakito & Nepakito & Pakito \\
\hline \multirow[t]{2}{*}{ Konsistencija } & Nepakito & Nepakito & Nepakito & Pakito \\
\hline & \multicolumn{4}{|c|}{$\begin{array}{c}\text { Lūpų balzamas su margalapès aktinidijos } \\
\text { uogomis }\end{array}$} \\
\hline Temperatūra & \multicolumn{2}{|c|}{$5 \pm 1{ }^{0} \mathrm{C}$} & \multicolumn{2}{|c|}{$18-25^{\circ} \mathrm{C}$} \\
\hline Laikymo laikas & 45 dienos & 90 dienų & 45 dienos & 90 dienų \\
\hline Kvapas & Nepakito & Nepakito & Nepakito & Pakito \\
\hline Spalva & Nepakito & Nepakito & Nepakito & Pakito \\
\hline Konsistencija & Nepakito & Nepakito & Nepakito & Pakito \\
\hline
\end{tabular}


buvo palikti stebèti 90 dienų. Tyrimas atliktas vieną dali lūpų balzamų laikant $+5^{\circ} \mathrm{C} \pm 1$ temperatūroje (šaldytuve), kitą dalị - ịprastinèmis sąlygomis $\left(18-25{ }^{\circ} \mathrm{C}\right.$ temperatūroje). Vertinami lūpų balzamų parametrai - tekstūra, kvapas, spalva. Šie parametrai buvo vertinami lūpų balzamus laikant skirtingomis sąlygomis 45 ir 90 dienų.

Statistinè duomenų analizė atlikta naudojant Microsoft Office Excel 2007 programą. Duomenys apdoroti taikant procentinių dažnių metodą. Naudojamų metodų tikslas - atskleisti respondentų nuomonę apie laboratorijoje pagamintų lūpų balzamų juslines savybes.

\section{Tyrimo rezultatai ir jų aptarimas}

Anoniminès apklausos metu respondentų teirautasi, kuris iš lūpų balzamų mėginių patiko labiau. Didesnè dalis respondentų (57,50 proc.) atsakè, kad labiau patiko lūpų balzamas, pagamintas su paprastosios avietés liofilizuotų uogų milteliais. Labiausiai respondentams patiko rusva lūpų balzamo spalva ir kieta konsistencija, kiek mažiau - kvapas. 42,50 proc. respondentų labiau patiko lūpų balzamas, pagamintas su margalapés aktinidijos liofilizuotų uogų milteliais. Esminè šio pasirinkimo priežastis buvo žalsva lūpų balzamo spalva ir kieta konsistencija.

Naudojant elektroninį termometrą, nustatyta pagamintų lūpų balzamų lydymosi temperatūra. Lūpų balzamo, kuriame buvo įmaišyta paprastosios avietės liofilizuotų uogų miltelių, lydymosi temperatūra buvo $34 \pm 1,0{ }^{\circ} \mathrm{C}$, o lūpų balzamo, kuriame buvo margalapés aktinidijos liofilizuotų uogų miltelių $-34,2 \pm 0,6{ }^{\circ} \mathrm{C}$. Pagal gautus rezultatus galima teigti, kad pagaminti lūpų balzamai atitinka Farmakopejoje reglamentuotus lydymosi temperatūros reikalavimus.

Pagaminus dvejopos sudèties lūpų balzamus (su paprastosios avietės ir margalapès aktinidijos liofilizuotų uogu milteliais), pamatuotos jų $\mathrm{pH}$ reikšmės. Tyrimų rezultatai pateikiami 1 lentelèje.

Moksliniuose šaltiniuose pateikiamos ịvairios augalinès sudèties lūpų balzamų pH reikšmès. Pastebèta, kad lūpų balzamų pH reikšmès neviršija 6,9 [7]. Galima daryti išvadą, jog pagamintų lūpų balzamų $\mathrm{pH}$ reikšmès yra moksliniuose šaltiniuose minimų $\mathrm{pH}$ reikšmių intervale.

Pagamintiems dvejopos sudèties lūpų balzamams su paprastosios avietės ir margalapés aktinidijos liofilizuotų uogų milteliais, atliktas stabilumo tyrimas. Preparatų stabilumas vertintas po pagaminimo praejus 45 dienoms ir 90 dienų. Remiantis moksliniais šaltiniais, reikšminga stabilumo tyrimą atlikti $18-25{ }^{\circ} \mathrm{C}$ ir $5 \pm 1{ }^{\circ} \mathrm{C}$ temperatūroje. Tyrimo rezultatai pateikiami 2 lenteleje.

Atliekant stabilumo tyrimus, po 90 dienų pastebèti 18-25 ${ }^{0} \mathrm{C}$ temperatūroje saugotų abiejų lūpų balzamų neryškūs spalviniai, kvapo ir konsistencijos pokyčiai. Abu lūpų balzamai pakeitė spalvą. Tos pačios sudèties lūpų balzamų, laikytų $5 \pm 1{ }^{0} \mathrm{C}$ temperatūroje, spalvos nepakito. Galima daryti išvadą, kad lūpų balzamų laikymui tinkamesnè žema aplinkos temperatūra.

\section{Išvados}

1. Juslinių savybių tyrimo metu atskleista, kad didesnei respondentu daliai labiau patiko lūpų balzamas, pagamintas su paprastujų aviečių liofilizuotų uogų milteliais. Pagrindiniai rezultatą nulèmę kriterijai - lūpų balzamo konsistencija, kvapas ir spalva. Kiek mažesnei apklaustujų daliai labiau patiko lūpų balzamas, pagamintas su margalapių aktinidijų liofilizuotų uogų milteliais, o pagrindiniai pasirinkimo kriterijai buvo lūpų balzamo spalva bei konsistencija.

2. Pagamintų lūpų balzamų lydymosi temperatūra yra aukštesnè, nei lūpų odos, todèl galima teigti, jog pagaminti lūpų balzamai atitinka Europos farmakopejoje reglamentuotus lydymosi temperatūros reikalavimus. Lūpų balzamai pasižymi silpnai rūgštinèmis savybėmis. Galima daryti išvadą, kad pagamintus preparatus tikslinga vartoti mikroorganizmų sukeltiems pažeidimams gydyti, apsaugai nuo išorinių veiksnių. Atliktas stabilumo tyrimas atskleide, kad preparatai tinkami vartoti iki 45 dienų.

\section{Literatūra}

1. Fernandes AR, Dario MF, Pinto CAS, Kaneko TM, Baby AR, Velasco MVR. Stability evaluation of organic lip balm. J Pharm Sci 2013;49(2):293-9.

https://doi.org/10.1590/S1984-82502013000200011

2. Yusof AAB, Azilah B, Sulaiman AZ, Naila A. Production of lip balm from stingless bee honey. J Mald National 2018;1(1)5772.

3. Kady M, Vishwasrao S, Singh S. Review on natural lip balm. J Res Cosm Sci 2015;5(1):1-7.

4. Langton AK, Alessi S, Hann M, Chien ALL, Kang S, Griffiths, CEM, Watson REB. Aging in skin of color: disruption to elastic fiber organization is detrimental to skin's biomechanical function. J Inv Derm 2018;139(4):779-788.

https://doi.org/10.1016/j.jid.2018.10.026

5. Meher DA, Alai MH, Nikam SP. Herbal lipstick formulation: a new approach. J Res Ayur Pharm 2011;2(6):1795-7.

6. Mukherjee S, Mitra R, Maitra A, Gupta S, Kumaran S, Chakrabortty A, Majumder PP. Sebum and hydration levels in specific regions of human face significantly predict the nature and diversity of facial skin microbiome. J Sci R 2016;6:36062 https://doi.org/10.1038/srep36062

7. Mishra P, Dwivedi S. Formulation and evaluation of lipstick containing herbal ingredients. J Med Pharm Res 2012;2(3):58-60.

8. Skrovankova S, Sumczynski D, Mlcek J, Jurikova T, Sochor J. Bioactive compounds and antioxidant activity in different types of berries. Int J Mol Sci 2015;16(10):24673-24706. 
https://doi.org/10.3390/ijms161024673

9. Silva PM, Gauche C, Gonzaga LV, Costa ACO, Fett R. Honey: chemical composition, stability and authenticity. J Food Chem 2016;196:309323.

https://doi.org/10.1016/j.foodchem.2015.09.051

\section{LIP BALMS WITH ACTINIDIA DAISY LEAF AND COMMON RASERRY LYOPHILIZED BERRIES MODELING AND QUALITY ASSESSMENT \\ B.Pockevičiūtè, R.Leonavičiūtè}

Keywords: lip balm, actinidia daisy leaf, common raspberry. Summary

Products of natural origin cause fewer allergic diseases and prevent the ingestion of microorganisms. The skin on the lips is very thin, which is why it is exposed to many external factors that can often lead to pigmented spots, cracks or even blisters. Based on an innovative and natural concept, lip balms are formulated in a semi-solid dosage form suitable for lip skin care. The object of the study is two laboratory lip balms of different compositions. The aim of the study was to develop semi-solid dosage forms with lyophilized berry powder of marginal actinidia, common raspberry and to evaluate their $\mathrm{pH}$ and stability at different temperatures after 45 and 90 days. Natural ingredients selected for lip balms: candelilla wax, shea butter, cocoa butter, sweet almond oil, natural bee honey, vitamin $\mathrm{E}$ and lyophilized raspberry and margarine actinidium berry powder, which added color and aroma to the balms. Lip balms are made by melting, melting the components above the water bath in descending order with honey, tocopherol and lyophilized berry powder at the end. An organoleptic study revealed that respondents liked lip balm containing freeze-dried raspberry, berry powder more in consistency, smell and color than lip balm, which contained margarine actinidia lyophilized powder in the base of the preparation. A study of $\mathrm{pH}$ values showed that lip balms have mildly acidic properties. It can therefore be concluded that the formulations are useful for the treatment of micro-organism damage and protection against external factors. Stability studies have shown that the formulations are stable for up to 45 days.

Correspondence to: birute.pockeviciute@go.kauko.lt

Gauta 2019-10-25 